\title{
Physiological effects and optimisation of nasal assist-control ventilation for patients with chronic obstructive pulmonary disease in respiratory failure
}

Christophe Girault, Virginie Chevron, Jean-Christophe Richard, Isabelle Daudenthun, Pierre Pasquis, Jacques Leroy, Guy Bonmarchand

\begin{abstract}
Background - A study was undertaken to investigate the effects of non-invasive assist-control ventilation (ACV) by nasal mask on respiratory physiological parameters and comfort in acute on chronic respiratory failure (ACRF).

Methods - Fifteen patients with chronic obstructive pulmonary disease (COPD) were prospectively and randomly assigned to two non-invasive ventilation (NIV) sequences in spontaneous breathing (SB) and ACV mode. ACV settings were always optimised and therefore subsequently adjusted according to patient's tolerance and air leaks.
\end{abstract}

Results - ACV significantly decreased all the total inspiratory work of breathing (WOBinsp) parameters, pressure time product, and oesophageal pressure variation in comparison with SB mode. The ACV mode also resulted in a significant reduction in surface diaphragmatic electromyographic activity to $36 \%$ of the control values and significantly improved the breathing pattern. SB did not change the arterial blood gas tensions from baseline values whereas ACV significantly improved both the $\mathrm{PaO}_{2}$ from a mean (SD) of 8.45 (2.95) kPa to 13.31 (2.15) $\mathrm{kPa}, \mathrm{PaCO}_{2}$ from $9.52(1.61) \mathrm{kPa}$ to $7.39(1.39) \mathrm{kPa}$, and the pH from $7.32(0.03)$ to $7.40(0.07)$. The respiratory comfort was significantly lower with ACV than with SB.

Conclusions - This study shows that the clinical benefit of non-invasive ACV in the management of ACRF in patients with COPD results in a reduced inspiratory muscle activity providing an improvement in breathing pattern and gas exchange. Despite respiratory discomfort, the muscle rest provided appears sufficient when ACV settings are optimised.

(Thorax 1997;52:690-696)

Keywords: non-invasive ventilation, assist-control mode, work of breathing, breathing pattern, respiratory comfort, acute on chronic respiratory failure, chronic obstructive pulmonary disease.

The clinical effectiveness of non-invasive ventilation (NIV) is now well established in the treatment of patients with chronic obstructive pulmonary disease (COPD) with acute on chronic respiratory failure (ACRF).$^{1-8}$ In these patients NIV could avoid the need for intubation in $50-70 \%$ of cases, thus reducing significantly the morbidity and duration of hospital stay. ${ }^{29}$ Administered via nasal or face mask, NIV can use assist-control (ACV) or pressure support ventilation (PSV). ${ }^{10}$ During ACV mode the ventilator delivers a positive pressure breath at a preset tidal volume in response to the patient's inspiratory effort or at a preset rate if no patient effort occurs within the preselected time period. The PSV mode is a pressure targeted mode in which each breath is patient triggered and supported. A preset positive airway pressure is maintained constant throughout the patient's spontaneous inspiratory effort, allowing patients to control their inspiratory flow, inspiratory time, and tidal volume. This is believed to increase patientventilator synchrony and comfort. However, there are potentially important physiological differences between these two NIV modes, especially in patients with COPD - for example, PSV may compensate for mask air leaks better than ACV but may deliver volumes less reliably, particularly in the presence of variable respiratory mechanics or unstable ventilatory drive. In addition, the PSV mode is not always available with the ventilators used. ${ }^{7}$ According to various authors and despite some contradictory results, ${ }^{11} \mathrm{ACV}^{357}$ and $\mathrm{PSV}^{12468}$ may provide similar results regarding success or failure in terms of the need for intubation. However, there have been few studies on the physiological mechanisms which could explain this clinical benefit. The physiological rationale for the usefulness of NIV in ACRF has been essentially studied with PSV $^{212}$ or pressurecontrolled ventilation very similar to PSV, ${ }^{4}$ and rarely with ACV mode. ${ }^{13}$ The physiological effects of NIV in patients with stable severe chronic respiratory failure have also been reported more with PSV ${ }^{14-17}$ than with the ACV mode. ${ }^{18}$ The physiological mechanism possibly responsible for the clinical benefit of NIV with ACV mode in ACRF has thus not been well studied and documented.

The objective of this study was therefore to investigate the effects of non-invasive ACV via a nasal mask on the physiological respiratory parameters - that is, respiratory muscle function, gas exchange and breathing pattern - as well as on respiratory comfort in an homogeneous population of COPD patients with ACRF. 


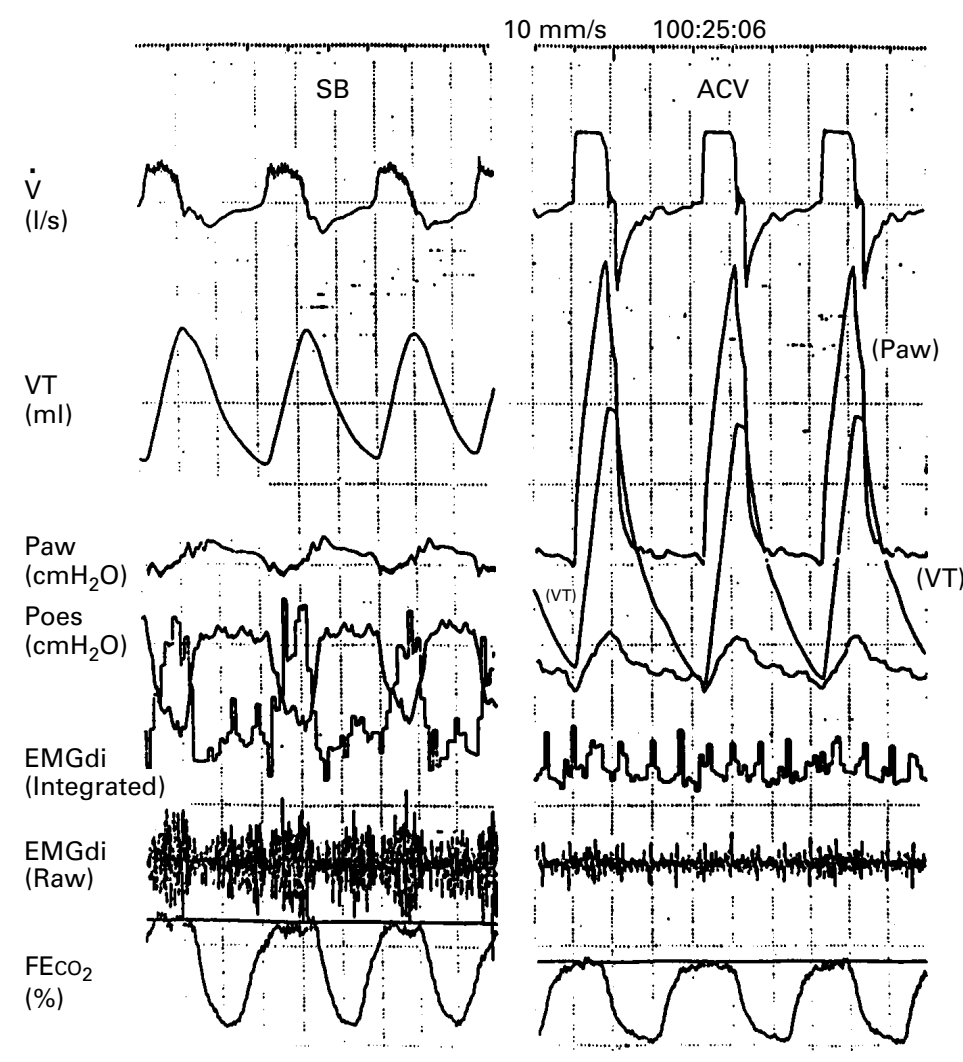

Figure 1 Representative polygraphic recordings $(10 \mathrm{~mm} / \mathrm{s})$ of respiratory mechanic parameters ( $V, V T$, Paw), oesophageal pressure (Poes), diaphragmatic electromyographic activity (raw and integrated EMGdi), and end tidal carbon dioxide fraction $\left(\mathrm{FETCO}_{2}\right)$ during non-invasive ventilation with spontaneous breathing (SB) and assist-control ventilation $(A C V)$ in patient 4 . Note the increase in $V T$ and Paw, and the decrease in Poes and EMGdi between $S B$ and $A C V$.

\section{Methods}

The study was conducted in a medical intensive care unit and approved by the ethical committee of the Charles Nicolle University Hospital. All patients gave their written informed consent. Patients enrolled in the study had known COPD or a high probability of the disease on the basis of the clinical history, physical examination, chest radiography, and/ or previous pulmonary function test data. Additional criteria for enrollment included hypercapnic acute respiratory failure requiring NIV according to the following criteria: ${ }^{24}$ tachypnoea $>25 / \mathrm{min}$ or bradypnoea $\leq 12 / \mathrm{min}, \mathrm{PaO}_{2}$ $\leq 8 \mathrm{kPa}(60 \mathrm{~mm} \mathrm{Hg})$ in ambient air, $\mathrm{PaCO}_{2}$ $\geq 6.5 \mathrm{kPa}(49 \mathrm{~mm} \mathrm{Hg})$ in ambient air or worsening with a low nasal oxygen flow ( $\leq 31 / \mathrm{min})$, respiratory acidosis ( $\mathrm{pH} \leq 7.35)$, a normal level of consciousness or moderate signs of respiratory encephalopathy (drowsiness, confusion, flapping tremor). Patients were included if they showed at least three of these criteria and if they tolerated NIV during the first few hours after admission. Patients with ACRF requiring immediate endotracheal intubation or any contraindication to the insertion of an oesophageal tube were not included.

STUDY PROTOCOL

The study was conducted during the 48 hours following admission for ACRF. Each patient was investigated fasting, in a semirecumbent position in bed, and in quiet conditions. Throughout the study patients were asked to close their mouth firmly in order to limit the deleterious effect of air leaks. ${ }^{13}$ All patients were randomly submitted to two consecutive NIV sequences via the same ventilator and nasal mask for a minimal duration of 30 minutes. One sequence in spontaneous breathing (SB) and supplemented with inspired oxygen was used as the patient's own control period, the patient breathing spontaneously through the ventilator circuit and nasal mask without any associated pressure support level. The other sequence was conducted in ACV mode. The patient was informed of the change in sequence, but was not aware of the type of ventilatory mode used (SB or ACV). Initial settings for ACV were those usually reported with NIV: ${ }^{71}$ insufflated tidal volume (VT) of $15-20 \mathrm{ml} / \mathrm{kg}$, respiratory rate (RR) of $12-20$ cycles $/ \mathrm{min}$, $\mathrm{TI} / \mathrm{Te}$ ratio of to $1 / 3$, inspired oxygen fraction $\left(\mathrm{FiO}_{2}\right)$ enabling arterial oxygen saturation $\left(\mathrm{SaO}_{2}\right)$ of $\geq 90 \%$, constant flow rate of $60 \mathrm{l} /$ min, trigger sensitivity of $-0.5 \mathrm{~cm} \mathrm{H}_{2} \mathrm{O}$. If necessary, these initial settings (VT, RR) were subsequently adjusted and thus optimised in relation to the patient's clinical tolerance and the presence or absence of air leaks around the mask before performing the measurements. The $\mathrm{FiO}_{2}$ did not change between SB and ACV. All measurements were made at the end of each ventilation sequence after at least 30 minutes of stable and appropriate ventilation.

Patients were observed clinically by a physician not involved in the procedure, as well as by continuous monitoring of heart rate, noninvasive blood pressure, and transcutaneous oximetry (Biox 3700, Ohmeda Inc, Boulder, Colorado, USA).

\section{MEASUREMENTS}

All patients were ventilated using the same ventilator (Evita 2, Dräger Medical Inc, Lubeck, Germany) and were connected to the ventilator via a tightly fitting nasal mask (Respironics, Murrysville, Pennsylvania, USA). The humidifier of the ventilator circuit was disconnected during the trial to decrease the workload necessary to overcome the circuit resistances. The following general data were recorded for all patients: past history, current diseases and treatment, arterial blood gas tensions on admission, and simplified acute physiological score (SAPS) ${ }^{20}$ Each patient was investigated using the same apparatus and polygraphic recorder (fig 1). Instantaneous flow rate was measured using a pneumotachograph (Fleisch No 1, Zurich, Switzerland) connected to a differential pressure transducer (Validyne MP45, Validyne Cor., Northridge, California, USA). The pneumotachograph was connected between the nasal mask and the Y-piece of the ventilator circuit. Corresponding volume variations (VT) were obtained by electrical integration of instantaneous flow rates. Minute ventilation $(\mathrm{VE})$ was defined as the product of VT and RR. Airway pressure (Paw) was measured at the nasal mask by a differential 
pressure transducer (Validyne MP45, Validyne Corporation, Northridge, California, USA). Oesophageal pressure (Poes), reflecting intrapleural pressure, was measured using the method described by Milic-Emili et $a l^{2122}$ via a latex balloon placed in the middle third of the oesophagus and connected to a differential pressure transducer (Validyne MP45). The proper position of the balloon was confirmed by an occlusion test. ${ }^{23}$ Variations in Poes ( $\Delta$ Poes), considered to be a parameter of inspiratory effort, were measured as the difference between minimum and maximum Poes. ${ }^{13}$ Dynamic intrinsic positive end-expiratory pressure (PEEPi,dyn), reflecting the end of the expiratory pressure gradient between the alveolus and the nasal mask, was measured on the Poes curve as the difference between point 0 and the Poes point corresponding to cancellation of insufflation flow, ${ }^{24}$ averaged from 10 representative cycles. Total inspiratory work of breathing (WOBinsp) was determined using Campbell's diagram method ${ }^{25}$ by integration of the area plotted between the pressure-volume (Poes-Vt) and the chest wall compliance $(\mathrm{Cw})$ curves. ${ }^{2627}$ Since it is impossible to measure $\mathrm{Cw}$ without complete relaxation, we assumed, as others have, ${ }^{2829}$ that it was equal to $4 \%$ of the theoretical vital capacity. ${ }^{30}$ WOBinsp was calculated from the mean of five cycles and expressed in joules (J). WOBinsp thus enabled calculation of WOBinsp in relation to VT (WOBinsp/VT in $\mathrm{J} / \mathrm{l}$ ) or to RR (WOBinsp/RR in $\mathrm{J} / \mathrm{min}$ ). Pressure time product (PTP), a better indicator of the energy expenditure of respiratory muscles, ${ }^{3132}$ was obtained from the product of TI and the area under the Poes curve corresponding to $T I$. In addition to $\Delta$ Poes, WOBinsp and PTP, respiratory muscle activity was evaluated by the diaphragmatic electromyogram (EMGdi) activity amplitude with bipolar skin surface electrodes. ${ }^{33}$ The EMGdi signal obtained (raw EMGdi) was then amplified (Universal amplifier 13-4615-58, Gould Electronics Inc, Cleveland, Ohio, USA) and filtered (30-300 Hz), rectified and electronically integrated every $100 \mathrm{~ms}$ (integrated EMGdi) to obtain a moving time average which was then analysed using the method of Lopata et al. ${ }^{34}$ The diaphragmatic activity was evaluated by the maximum or peak amplitude of the integrated EMGdi signal (pEMGdi). This quantitative value, averaged from 10 cycles, was also expressed as a percentage of the control value obtained in SB.

The end tidal carbon dioxide fraction $\left(\mathrm{FETCO}_{2}\right)$ and $\mathrm{SaO}_{2}$ were measured continuously, respectively, at the mask using a rapidly responding $\mathrm{CO}_{2}$ analyser (Medical Gas Analyzer LB-2, Sensor Medics Corp, Anaheim, California, USA) and by transcutaneous pulsed oximetry (Biox 3700, Ohmeda Inc, Boulder, Colorado, USA). Arterial blood gas tensions, sampled by radial catheter at the end of each ventilation period, were immediately analysed (ABL3, Radiometer Inc, Copenhagen, Denmark). The end tidal $\mathrm{CO}_{2}$ pressure $\left(\mathrm{PeTCO}_{2}\right)$ was calculated from the cycles in which VT, TI, TE, Ttot and $\mathrm{FETCO}_{2}$ were measured.
All signals (Vं, Vt, Paw, Poes, Fetco 2 and EMGdi) were simultaneously displayed and recorded using a polygraphic recorder (ES 2000 V12, Gould Electronics Inc, Cleveland, Ohio, USA) (fig 1). Polygraphic recordings of 10-15 respiratory cycles with a paper speed of 10 and $50 \mathrm{~mm} / \mathrm{s}$ were used to measure $\mathrm{VT}$, inspiratory $(\mathrm{TI})$ and expiratory $(\mathrm{TE})$ times, total cycle duration (Ttot), RR, mean inspiratory flow (VT/TI), relative inspiratory time (TI/ Ttot), and $\mathrm{FETCO}_{2}$ for each cycle. They were then averaged from the entire tracing. A digitisation table (Hewlett Packard $9874 \mathrm{~A}$ ) and a personal computer (Hewlett Packard 9835 A) were used for measurements and calculations on each entire recording.

The respiratory comfort (level of dyspnoea, well being) was assessed in the last minutes of each ventilation sequence on a $100 \mathrm{~mm}$ visual analogue scale (VAS). The patient's status was located between a value of 0 ("I don't feel at all comfortable") and 100 ("I feel very comfortable") and converted into a numerical value for statistical analysis. Preference for each of the two modes was also noted.

\section{STATISTICAL ANALYSIS}

The primary end point involved comparison of respiratory muscle function parameters, gas exchange, and breathing pattern between the SB and ACV modes. The secondary end point evaluated the clinical respiratory comfort with these two modes. Qualitative data assessed by VAS were subsequently converted into numerical values in millimetres. Due to the crossover design of the trial, we performed a nonparametric test for carry-over (interaction), period and treatment effects using the MannWhitney U test to compare results between SB and ACV sequences. ${ }^{35}$ The Wilcoxon test for paired data was used to compare arterial blood gas tensions on admission with those obtained with ACV and SB mode. Results were expressed as mean (SD) for ACV and SB separately and median differences and ranges (ACV-SB). A difference was considered to be statistically significant for an alpha probability of less than $0.05(\mathrm{p}<0.05)$.

\section{Results}

The main clinical and respiratory characteristics of the 15 patients with COPD are shown in table 1 . All showed evidence of severe hypercapnic ACRF requiring NIV. These ACRF episodes were related to bronchial infection in 14 cases and to pneumonia in one case (patient 3). Table 1 also shows the main ventilatory settings used in ACV mode during the trial after optimisation. No evidence was found for any carry-over (interaction) or period effects so all the results presented are for the non-parametric treatment effects.

In comparison with $\mathrm{SB}$, all the WOBinsp parameters (WOBinsp/cycle, WOBinsp/VT, WOBinsp/RR), and PTP were significantly decreased with ACV ( $<<0.001$; table 2) and all patients demonstrated a decrease in their individual values. The pEMGdi was also sig- 
Table 1 Clinical and respiratory characteristics of the 15 patients with COPD on admission and settings used with assist-control ventilation (AVC)

\begin{tabular}{|c|c|c|c|c|c|c|c|c|c|c|c|c|c|}
\hline $\begin{array}{l}\text { Patient } \\
\text { no. }\end{array}$ & Sex & $\begin{array}{l}\text { Age } \\
\text { (years) }\end{array}$ & $\begin{array}{l}\text { Weight } \\
(\mathrm{kg})\end{array}$ & $\begin{array}{l}F E V_{1} \dagger \\
(\% \text { pred })\end{array}$ & $\begin{array}{l}V C \dagger \\
\text { (\% pred) }\end{array}$ & $\begin{array}{l}F E V_{1} / V C \dagger \\
(\%)\end{array}$ & $\begin{array}{l}\mathrm{PaO}_{2}{ }^{*} \\
(\mathrm{kPa})\end{array}$ & $\begin{array}{l}\mathrm{PaCO}_{2}{ }^{*} \\
(\mathrm{kPa})\end{array}$ & $p H^{*}$ & SAPS & $\begin{array}{l}V_{T} \\
(\mathrm{ml})\end{array}$ & $\begin{array}{l}R R \\
\text { (cycles/min) }\end{array}$ & $\begin{array}{l}\mathrm{FiO}_{2} \\
(\%)\end{array}$ \\
\hline 1 & M & 54 & 57 & 24 & 60 & 33 & 6.98 & 8.94 & 7.33 & 8 & 840 & 12 & 0.3 \\
\hline 2 & $\mathrm{~F}$ & 71 & 50 & - & - & - & 9.61 & 8.46 & 7.34 & 11 & 750 & 14 & 0.3 \\
\hline 3 & $\mathrm{~F}$ & 65 & 72 & - & - & - & 4.69 & 7.18 & 7.35 & 7 & 500 & 12 & 0.4 \\
\hline 4 & $\mathrm{~F}$ & 68 & 40 & 32 & 42 & 59.79 & 8.86 & 10.47 & 7.27 & 9 & 750 & 18 & 0.4 \\
\hline 5 & M & 52 & 66 & 16 & 37 & 34.42 & 6.60 & 9.99 & 7.34 & 10 & 600 & 18 & 0.4 \\
\hline 6 & $M$ & 74 & 69 & - & - & - & 4.53 & 9.04 & 7.32 & 14 & 600 & 12 & 0.5 \\
\hline 7 & $M$ & 60 & 51 & 23 & 62 & 28.95 & 8.27 & 7.95 & 7.35 & 8 & 700 & 17 & 0.4 \\
\hline 8 & $M$ & 69 & 106 & 53 & 63 & 62.50 & 5.62 & 7.55 & 7.32 & 10 & 800 & 12 & 0.4 \\
\hline 9 & $M$ & 60 & 59 & 20 & 53 & 29.84 & 5.05 & 9.15 & 7.32 & 10 & 800 & 12 & 0.4 \\
\hline 10 & $M$ & 68 & 83 & 34 & 59 & 45.12 & 8.18 & 9.93 & 7.35 & 12 & 600 & 15 & 0.4 \\
\hline 11 & $M$ & 71 & 59 & - & - & - & 10.96 & 11.43 & 7.24 & 10 & 500 & 20 & 0.45 \\
\hline 12 & $M$ & 58 & 58 & 32 & 72 & 35.37 & 11.27 & 9.63 & 7.33 & 10 & 700 & 15 & 0.45 \\
\hline 13 & $M$ & 70 & 61 & 34 & 48 & 55.09 & 6.17 & 11.62 & 7.27 & 11 & 700 & 15 & 0.30 \\
\hline 14 & $M$ & 67 & 80 & - & - & - & 9.91 & 8.40 & 7.32 & 9 & 800 & 13 & 0.40 \\
\hline 15 & $M$ & 61 & 53 & 24 & 39 & 48.05 & 11.10 & 12.99 & 7.30 & 7 & 600 & 20 & 0.40 \\
\hline Mean & - & 64.53 & 64.27 & 29.20 & 53.50 & 43.21 & 8.45 & 9.52 & 7.32 & 9.73 & 682.67 & 15.0 & 0.39 \\
\hline (SD) & & $(6.75)$ & $(16.21)$ & $(10.43)$ & (11.65) & (12.65) & $(2.93)$ & $(1.61)$ & $(0.03)$ & (1.87) & $(110.22)$ & (2.95) & $(0.06)$ \\
\hline
\end{tabular}

SAPS = simplified acute physiological score; $\mathrm{VT}=$ insufflated tidal volume; $\mathrm{RR}=$ respiratory rate.

* Arterial blood gas tension on admission in ambient air or with additional oxygen $\leq 31 / \mathrm{min}$.

† Pulmonary function tests in steady state.

nificantly reduced $(\mathrm{p}=0.004)$ with a decrease of $36 \%$ with ACV in comparison with control values in SB mode. The mean Paw was significantly higher with ACV ( $\mathrm{p}<0.001)$. PEEPi, dyn did not change between the two NIV

Table 2 Effects of ACV on respiratory mechanic parameters and diaphragmatic function during non-invasive ventilation in 15 patients with $C O P D$

\begin{tabular}{lcclc}
\hline & \multicolumn{1}{c}{$S B$} & $A C V$ & $A C V-S B$ & $p$ value \\
\hline Paw $\left(\mathrm{cm} \mathrm{H}_{2} \mathrm{O}\right)$ & $0.23(0.39)$ & $6.71(1.99)$ & $6.55(2.25$ to 9.30$)$ & $<0.001$ \\
PEEPi, dyn (cm $\left.\mathrm{H}_{2} \mathrm{O}\right)$ & $5.08(2.74)$ & $4.90(4.02)$ & $-0.50(-4.90$ to 4.30$)$ & NS \\
$\Delta \mathrm{Poes}\left(\mathrm{cm} \mathrm{H} \mathrm{H}_{2} \mathrm{O}\right)$ & $22.03(7.86)$ & $6.69(5.13)$ & $-13.00(-35.70$ to 0.50$)$ & $<0.001$ \\
pEMGdi $(\mathrm{mV})$ & $119(64.52)$ & $70.60(52.24)$ & $-42.80(-168$ to 78.80$)$ & 0.004 \\
WOBinsp (J) & $0.83(0.34)$ & $0.38(0.35)$ & $-0.38(-1.02$ to 0.05$)$ & $<0.001$ \\
WOBinsp/VT (J/1) & $1.90(0.64)$ & $0.58(0.52)$ & $-1.27(-2.18$ to -0.56$)$ & $<0.001$ \\
WOBinsp/RR (J/min) & $17.08(8.12)$ & $6.95(7.05)$ & $-11.57(-19.71$ to -1.39$)$ & $<0.001$ \\
PTP $\left(\mathrm{cm} \mathrm{H}_{2} \mathrm{O} / \mathrm{s}\right)$ & $18.01(6.07)$ & $4.05(3.97)$ & $-11.90(-26.41$ to -6.87$)$ & $<0.001$ \\
\hline
\end{tabular}

$\mathrm{ACV}=$ assist-control ventilation; $\mathrm{SB}=$ spontaneous breathing; Paw $=$ mean airway pressure; $\mathrm{PEEPi}, \mathrm{dyn}=$ dynamic intrinsic positive end expiratory pressure; $\Delta \mathrm{Poes}=$ changes in oesophageal pressure; $\mathrm{pEMGdi}=$ maximal integrated diaphragmatic electromyographic activity; WOBinsp = total inspiratory work of breathing; $\mathrm{VT}=$ tidal volume; $\mathrm{RR}=$ respiratory rate; $\mathrm{PTP}=$ pressure time product.

Values are mean $(\mathrm{SD})$ and median differences (ACV - SB) (ranges); $\mathrm{p}$ values SB versus ACV.
.

Table 3 Effects of $A C V$ on breathing pattern during non-invasive ventilation in 15 patients with COPD

\begin{tabular}{lcccc}
\hline & $S B$ & $A C V$ & $A C V-S B$ & $p$ value \\
\hline VT (ml) & $423.40(99.33)$ & $617.60(116.41)$ & $183(29$ to 356$)$ & $<0.001$ \\
RR (cycles/min) & $20.58(3.62)$ & $17.43(3.02)$ & $-3.7(-9.20$ to 3.90$)$ & 0.01 \\
VE (1/min) & $8.99(2.43)$ & $10.65(1.98)$ & $1.72(-5.44$ to 4.68$)$ & 0.02 \\
Ti (s) & $1.13(0.20)$ & $0.86(0.26)$ & $-0.29(-0.76$ to 0.23$)$ & 0.01 \\
TE (s) & $1.89(0.50)$ & $2.67(0.64)$ & $0.79(-0.43$ to 1.57$)$ & 0.002 \\
Ttot (s) & $3.02(0.67)$ & $3.54(0.61)$ & $0.60(-1.17$ to 1.69$)$ & 0.028 \\
TI/Ttot & $0.38(0.03)$ & $0.25(0.08)$ & $-0.12(-0.22$ to 0.005$)$ & $<0.001$ \\
VT/Tr (1/s) & $0.38(0.08)$ & $0.77(0.22)$ & $0.38(0.01$ to 0.88$)$ & $<0.001$ \\
\hline
\end{tabular}

$\mathrm{ACV}=$ assist-control ventilation; $\mathrm{SB}=$ spontaneous breathing; $\mathrm{VT}=$ tidal volume; $\mathrm{RR}=$ respiratory rate; $\mathrm{VE}=$ minute ventilation; $\mathrm{TI}=$ inspiratory time; $\mathrm{TE}=$ expiratory time; $\mathrm{T}$ tot $=$ total breathing cycle time; $\mathrm{TI} / \mathrm{T}$ tot $=$ duty cycle; $\mathrm{VT} / \mathrm{TI}=$ mean inspiratory flow.

Vyclues are mean $(\mathrm{SD})$ and median differences $(\mathrm{ACV}-\mathrm{SB}$ ) (ranges); $\mathrm{p}$ values $\mathrm{SB}$ versus $\mathrm{ACV}$.
Valuen

Table 4 Effects of $A C V$ on gas exchange during non-invasive ventilation in 15 patients with COPD

\begin{tabular}{|c|c|c|c|c|}
\hline & $S B$ & $A C V$ & $A C V-S B$ & $p$ value \\
\hline $\mathrm{PaO}$ & 1 & 13.31 & $1.13(-2.53$ to 6 & 0.02 \\
\hline $\mathrm{PaO}_{2} / \mathrm{FiO}_{2}(\mathrm{~mm} \mathrm{Hg})$ & $232.33(45.37)$ & $267.96(77.35)$ & $18.89(-47$ to 16$)$ & 0.02 \\
\hline $\mathrm{SaO}_{2}(\%)$ & $95.71(1.66)$ & $97.23(1.11)$ & $1.60(-0.70$ to 4.3$)$ & 0.002 \\
\hline $\mathrm{pH}$ & $7.35(0.05)$ & $7.40(0.07)$ & 0.03 (0 to 0.19$)$ & $<0.001$ \\
\hline $\mathrm{PaCO}_{2}(\mathrm{kPa})$ & $8.51(1.32)$ & 7.39 (1.39) & $-0.77(-3.52$ to 0.25$)$ & $<0.001$ \\
\hline $\mathrm{HCO}_{3}^{-}(\mathrm{mmol} / \mathrm{l})$ & $34.50(4.28)$ & $33.51(4.37)$ & $-1.30(-3.5$ to 1$)$ & 0.02 \\
\hline $\mathrm{PETCO}_{2}(\mathrm{~mm} \mathrm{Hg})$ & $48.50(8.33)$ & $43.12(8.26)$ & $-3.50(-47$ to 160$)$ & $<0.001$ \\
\hline
\end{tabular}

$\mathrm{ACV}=$ assist-control ventilation; $\mathrm{SB}=$ spontaneous breathing; $\mathrm{PETCO}_{2}=$ end tidal $\mathrm{CO}_{2}$ pressure; $\mathrm{PaO}_{2}, \mathrm{PaCO}_{2}=$ arterial oxygen and carbon dioxide pressures; $\mathrm{SaO}_{2}=$ oxygen saturation. Values are mean (SD) and median differences (ACV - SB) (ranges); $\mathrm{p}$ values $\mathrm{SB}$ versus $\mathrm{ACV} .1 \mathrm{kPa}=$ $7.5 \mathrm{mmHg}$. sequences while $\Delta$ Poes was significantly decreased with ACV ( $\mathrm{p}<0.001)$.

The effects of NIV on breathing pattern are shown in table 3 . VE was significantly increased with ACV $(p=0.02)$ compared with SB. This improvement in $\mathrm{VE}$ was achieved by a significant increase in VT $(\mathrm{p}<0.001)$ while a parallel decrease in $R R$ was observed $(p=0.01)$. This last finding during ACV was related to an increase in Ttot $(p=0.028)$ due to a significant increase in $\operatorname{TE}(\mathrm{p}=0.002)$ and a decrease in $\mathrm{TI}$ $(p=0.01)$. ACV also significantly affected $\mathrm{TI} /$ Ttot $(\mathrm{p}<0.001)$ and increased VT/TI ( $\mathrm{p}$ $<0.001$ ) in comparison with SB.

A comparison of arterial blood gas tensions on admission with those obtained with ACV revealed a significant increase in $\mathrm{PaO}_{2}$ (mean (SD) 8.45 (2.93) vs 13.31 (2.15); p <0.001) with a parallel improvement in $\mathrm{PaCO}_{2}(9.52$ (1.61) vs 7.39 (1.39); $\mathrm{p}=0.001)$ and $\mathrm{pH}(7.32$ (0.03) vs $7.40(0.07) ; \mathrm{p}=0.0009)$. No change was found between arterial blood gas tensions on admission and those obtained with SB mode. During the trial oxygenation parameters were also significantly improved between SB and $\mathrm{ACV}$ although $\mathrm{FiO}_{2}$ did not change between the two sequences. Among the alveolar ventilation parameters baseline $\mathrm{pH}, \mathrm{PaCO}_{2}$, and $\mathrm{PETCO}_{2}$ were significantly improved with ACV ( $\mathrm{p}<0.001$; table 4).

The mean (SD) VAS rating for respiratory comfort was 57.23 (30.12) $\mathrm{mm}$ during ACV, significantly smaller than that during SB mode at $77.46(14.66) \mathrm{mm}$ with a mean difference of $24 \mathrm{~mm}(95 \% \mathrm{CI}-10$ to $80 \mathrm{~mm}, \mathrm{p}=0.05)$, indicating that ACV was less acceptable to the patients.

None of the 15 patients with COPD finally required intubation. All were subsequently successfully managed with daily NIV using ACV in 10 cases and PSV in five who profited more by this last mode in the long term.

\section{Discussion}

This study provides a better understanding of the physiological mechanisms underlying the clinical benefits which may be expected from NIV with ACV mode in the treatment of acute 
exacerbations of COPD. It shows that, during NIV, ACV acts by reducing total WOBinsp while at the same time improving breathing pattern and gas exchange. Despite optimised settings adapted to the clinical tolerance of patients, these beneficial physiological effects are achieved at the expense of respiratory discomfort which is experienced by all patients in comparison with the SB mode.

The conditions of this study involved the usual emergency situation in which such patients are admitted. We used initial ACV settings as previously reported ${ }^{711}$ but it proved necessary in most patients to change these settings subsequently for reasons of tolerance or air leaks around the nasal mask. We found that a lower than recommended ${ }^{711}$ mean insufflated VT of $9 \mathrm{ml} / \mathrm{kg}$ provided a significant, and probably sufficient, reduction in WOBinsp with improved breathing pattern. This optimisation was nevertheless subject to interindividual variations which had to be taken into account when interpreting our results and setting ventilators. It is thus probable that settings suggested up to now ${ }^{71}$ - which can be obtained only at the price of an increased Paw (that is, by increasing VT with ACV) - would have led to a greater decrease in WOBinsp but at the expense of more patient discomfort. It is essential to take this fact into account when choosing initial settings from NIV. Furthermore, our settings did not cause any significant variation in PEEPi,dyn which may contribute, particularly in COPD, ${ }^{36}$ to an additional imposed workload via dynamic hyperinflation as has sometimes been observed with non-invasive PSV. ${ }^{212}$ The optimised settings presented in this study could constitute baseline settings for future use of non-invasive ACV.

We used several parameters to evaluate inspiratory muscle function, and more especially that of the diaphragm. To the best of our knowledge, calculation of WOBinsp with NIV is reported here for the first time. During ACV we did not calculate the work performed by the patient as the difference between ventilator work during assisted and controlled mechanical breaths with identical flow rates and tidal volumes $^{37}$ because this method is not applicable during SB.

Our results demonstrate a significant reduction in muscle activity indices when using NIV with the ACV mode compared with the SB mode, with $\Delta$ Poes, WOBinsp/VT, WOBinsp/RR, and PTP being influenced the most. The baseline total workload was changed from a value that was close to the diaphragmatic fatigue threshold of $1.40 \mathrm{~J} / 1^{38}$ to a normal value of $0.30-0.65 \mathrm{~J} / 1 .{ }^{30}$ This difference in total WOBinsp between the SB and ACV modes could be due in part to the workload necessary to overcome the circuit and demand valve resistances. ${ }^{29}$ Nevertheless, as explained below, most of the cycles were also triggered during $\mathrm{ACV}$ in our patients. Interestingly, the WOB of the patients with the ACV mode was less than that reported in other studies with invasive endotracheal ventilation. ${ }^{313739}$ The size of the endotracheal tubes can greatly influence the muscular effort required, ${ }^{4041}$ and air leaks dur- ing NIV due to a poorly fitting mask or unsuitable settings also increase respiratory workload. ${ }^{13}$ Despite these possible limitations we found that non-invasive ACV can, like endotracheal ventilation, achieve one of the goals of assisted ventilation which is to provide muscle rest. ${ }^{4}$ Complete muscle rest could not be achieved during the trial because a certain degree of muscle activity persists with ACV, although this activity is close to normal. ${ }^{30}$ This is because we used a patient triggered mode of ventilation (ACV) to assist our patients. Even with endotracheal ventilation, ACV may allow considerable respiratory effort to persist which can be similar to the effort needed with SB..$^{313742}$

The interpretation of WOBinsp may be difficult with NIV so we combined measurement of the EMGdi. It has been shown that during NIV the surface EMGdi activity was well correlated with that of EMGdi assessed by invasive oesophageal electrodes. ${ }^{1343}$ The results parallelled those of WOBinsp - that is, a substantial reduction in surface EMGdi amplitude occurred with the ACV mode. The decrease in WOBinsp and EMGdi with non-invasive ACV was also supported by the decrease in $\triangle$ Poes and PTP. These parameters, which are easier to obtain and interpret in clinical practice, are also good indices of muscle energy expenditure and oxygen consumption in response to the ventilatory drive of patients. ${ }^{133132}$

Our results support those of previous physiological studies of NIV in ACRF. ${ }^{21213}$ These studies mainly investigated $\mathrm{PSV}^{212}$ rather than the ACV mode. ${ }^{13}$ The WOBinsp was not calculated but a significant reduction was found in transdiaphragmatic pressure (Pdi), $\mathrm{PTP}^{212}$ electrical activity of the diaphragm, ${ }^{21213}$ and $\Delta$ Poes in patients with chronic obstructive or restrictive respiratory disease. ${ }^{13}$ Similar results with PSV using a mask have also been reported in patients with stable COPD. ${ }^{14-17}$ To the best of our knowledge, no previous study has specifically evaluated the physiological effects of ACV during NIV in a large population of COPD patients with ACRF. Carrey et $a l^{13}$ first reported the effects of NIV on inspiratory muscle activity. However, they used a pressure control mode and only investigated two patients with COPD in ACRF of a study population of 12 subjects.

Our study also shows that NIV with ACV mode enables an improvement in the breathing pattern as has already been shown with PSV in other patients. ${ }^{212} \mathrm{ACV}$ thus acts essentially as expected by increasing alveolar ventilation (VT) and reducing RR with consequent improvement in arterial blood gas tensions. It is possible that the arterial blood gas tensions in our patients could have improved spontaneously during the delay (mean (SD) 19.2 (11.48) hours) between their admission and the start of the study. However, the blood gas tensions during SB did not differ from the admission values, suggesting this did not occur. Our arterial blood gas tensions are in agreement with those of numerous clinical ${ }^{1-8}$ and physiological $^{12}$ studies with NIV in ACRF. Our findings indicate that improved alveolar ventilation can be expected within 30 minutes of starting 
$\mathrm{NIV}^{744}$ and this supports the view that NIV is of most benefit to patients with acute hypercapnic respiratory failure. ${ }^{44}$

The respiratory comfort of our patients was an essential factor for the acceptance and subsequent results of the NIV technique. The physiological effects of NIV could certainly be improved if it was not necessary to take into account this criterion. Despite the fact that we optimised the settings for ACV, all our patients preferred SB and PSV to the ACV mode in terms of respiratory comfort. A recent study to assess non-invasive ACV and PSV modes in 29 patients $^{19}$ found that PSV was also better accepted and had fewer side effects than ACV. The anomaly that, despite adequate respiratory muscle rest with the ACV mode our patients experienced discomfort, could be related to the increase in Paw or the loss of control of breathing by ACV compared with the SB mode. Although we failed to demonstrate any correlation between Paw and VAS ratings, these explanations probably account for the fact that PSV is better tolerated than ACV but without any difference in clinical results. ${ }^{19}$

In conclusion, we have shown that the use of non-invasive ACV in patients with COPD with ACRF results in a substantial decrease in the workload of the respiratory muscles with improvements in breathing pattern and gas exchange. These physiological effects are maximised if the ventilator settings are optimally adjusted according to the patient's tolerance and the presence of air leaks. The main disadvantage of the ACV mode in the short term appears to be a feeling of respiratory discomfort experienced by the patients so physicians must optimise the ACV settings to improve the success of the technique. If respiratory comfort is the limiting factor then PSV may be preferable to ACV, although the ACV mode might be more physiologically appropriate during the early phase of ACRF in some patients with COPD who have unreliable inspiratory effort, unstable ventilatory drive, and variable respiratory mechanics.

The authors would like to thank Jean-François Gibon, Françoise Burel, and Yann Lacoume for their valuable technical assistance, and Marie-France Hellot and Jacques Benichou for their statistical assistance.

1 Meduri GU, Conoscenti CC, Menashe P, Nair S. Noninvasive face mask ventilation in patients with acute resinvasive face mask ventilation in patien

2 Brochard L, Isabey D, Piquet J, Amaro P, Mancebo J, Messadi AA, et al. Reversal of acute exacerbations of chronic obstructive lung disease by inspiratory assistance with a face mask. N Engl f Med 1990;323:1523-30.

3 Marino W. Intermittent volume cycled mechanical ventilation via nasal mask in patients with respiratory failure due to COPD. Chest 1991;99:681-4.

4 Meduri GU, Abou-Shala N, Fox RC, Jones CB, Leeper KV, Wunderink RG. Noninvasive face mask mechanical ventilation in patients with acute hypercapnic respiratory failure. Chest 1991;100:445-54.

5 Chevrolet JC, Jolliet P, Abajo B, Toussi A, Louis M. Nasal positive pressure ventilation in patients with acute respositive pressure ventilation in patients

6 Pennock BE, Kaplan PD, Carlin BW, Sabangan JS, Magovern JA. Pressure support ventilation with a simplified
ventilatory support system administered with a nasal mask ventilatory support system administered with a nasal mask in pati

7 Benhamou D, Girault C, Faure C, Portier F, Muir JF. Nasal mask ventilation in acute respiratory failure: experience in elderly patients. Chest 1992;102:912-17.

8 Fernandez R, Blanch LI, Valles J, Baigorri F, Artigas A. Pressure support ventilation via face mask in acute respiratory failure in hypercapnic COPD patients. Intensive Care Med 1993;19:456-61.
9 Brochard L, Mancebo J, Wysocki M, Lofaso F, Conti G, Rauss A, et al. Noninvasive ventilation for acute exacerbations of chronic obstructive pulmonary diease. $N$ Engl f Med 1995;333:817-22.

10 Branthwaite MA. Non-invasive and domiciliary ventilation: positive pressure techniques. Thorax 1991;46:208-12.

11 Foglio C, Vitacca M, Quadrio A, Scalvini S, Marangoni $\mathrm{S}$, Ambrosino N. Acute exacerbations in severe COLD patients. Treatment using positive pressure ventilation by nasal mask. Chest 1992; 101:1533-8.

12 Appendini L, Patessio A, Zanaboni S, Carone M, Gukov B, Donner CF, et al. Physiologic effects of positive endexpiratory pressure and mask pressure support during expiratory pressure and mask pressure support during Am $\mathcal{F}$ Respir Crit Care Med 1994;149:1069-76.

13 Carrey Z, Gottfried SB, Levy RD. Ventilatory muscle support in respiratory failure with nasal positive pressure ventilation. Chest 1990;97:150-8.

14 Ambrosino N, Nava S, Bertone P, Fracchia C, Rampulla C. Physiologic evaluation of pressure support ventilation by nasal mask in patients with stable COPD. Chest 1992 101:385-91.

15 Nava S, Ambrosino N, Rubini F, Fracchia C, Rampulla C, Torri G, et al. Effect of nasal pressure support ventilation and external PEEP on diaphragmatic activity in patients with severe stable COPD. Chest 1993;103:143-50.

16 Lien TC, Wang JH, Chang MT, Kuo CD. Comparison of BiPAP nasal ventilation and ventilation via iron lung in severe stable COPD. Chest 1993;104:460-6.

17 Renston JP, DiMarco AF, Supinski GS. Respiratory muscle rest using nasal BiPAP ventilation in patients with stable severe COPD. Chest 1994;105:1053-60.

18 Elliott MW, Mulvey DA, Moxham J, Green M, Branthwaite MA. Domiciliary nocturnal nasal intermittent positive pressure ventilation in COPD: mechanisms underlying changes in arterial blood gas tensions. Eur Respir 7 1991; 4:1044-52.

19 Vitacca M, Rubini F, Foglio K, Scalvini S, Nava S, Ambrosino N. Non-invasive modalities of positive pressure ventilation improve the outcome of acute exacerbations ventilation improve the outcome of acute exacerbations

20 Le Gall JR, Loirat P, Alperovitch A, Glaser P, Granthil C, Mathieu D, et al. A simplified acute physiologic score for ICU patients. Crit Care Med 1984;12: 975-7.

21 Milic-Emili J, Mead J, Turner JM. Improved technique for estimating pleural pressure from esophageal balloons. $\mathscr{F}$ Appl Physiol 1964;19:207-11.

22 Milic-Emili J, Mead J, Turner JM. Topography of esophageal pressure as a function of posture in man. $7 \mathrm{Appl}$ Physiol 1964;19:212-7.

23 Baydur A, Behrakis PK, Zin NA, Milic-Emili J. A simple method for assessing the validity of the esophageal balloon technique. Am Rev Respir Dis 1982;126:788-91.

24 Smith TC, Marini JJ. Impact of PEEP on lung mechanics and work of breathing in severe airflow obstruction. $₹ A p p l$ Physiol 1988;5:1488-99.

25 Campbell EJM, Westlake EK, Cherniack RM. Simple method of estimating oxygen consumption and efficiency of the muscles of breathing. F Appl Physiol 1957;11:303-8.

26 Annat G, Viale JP. Measuring the breathing workload in mechanically ventilated patients. Intensive Care Med 1990 16:418-21.

27 Banner MJ, Jaeger MJ, Kirby RR. Components of the work of breathing and implications for monitoring ventilatordependent patients. Crit Care Med 1994;22:515-23.

28 Fleury B, Murciano D, Talamo C, Aubier M, Pariente R, Milic-Emili J. Work of breathing in patients with chronic obstructive pulmonary disease in acute respiratory failure. Am Rev Respir Dis 1985;131:822-7.

29 Beydon L, Chasse M, Harf A, Lemaire F. Inspiratory work of breathing during spontaneous ventilation using demand valves and continuous flow systems. Am Rev Respir Dis 1988;138:300-4.

30 Quanjer P. Standardized lung function testing. Bull Eur Physiopathol Respir 1983;19(Suppl 5):1-95.

31 Marini JJ, Smith TC, Lamb VJ. External work output and force generation during synchronized intermittent mechanical ventilation. Am Rev Respir Dis 1988;138:116979.

32 Field S, Sanci S, Grassino A. Respiratory muscle oxygen consumption estimated by the pressure-time index. $\mathcal{F} A p p l$ Physiol 1984;57:44-51.

33 Lansing R, Savelle J. Chest surface recording of diaphragm potentials in man. Electroencephalogr Clin Neurophysiol 1989;72:59-68

34 Lopata M, Evanich MJ, Lourenco RV. Quantification of diaphragmatic EMG response to $\mathrm{CO}_{2}$ rebreathing in humans. F Appl Physiol 1977;43:262-70.

35 Hills $M$, Armitage P. The two period cross-over clinical trial. Br f Clin Pharmacol 1979;8:7-20.

36 Coussa ML, Guérin C, Eissa NT, Corbeil C, Chasse M, Braidy J, et al. Partitioning of work of breathing in mechanically ventilated COPD patients. F Appl Physiol 1993; 75:1711-9.

37 Marini JJ, Rodriguez RM, Lamb V. The inspiratory workload of patient-initiated mechanical ventilation. Am Rev Respir Dis 1986;134:992-9.

38 Bellemare F, Grassino A. Evaluation of human diaphragm fatigue. F Appl Physiol 1982;53:1196-206.

39 Kreit JW, Capper MW, Eschenbacher WL. Patient work of breathing during pressure support and volume-cycled mechanical ventilation. Am f Respir Crit Care Med 1994, 149:1085-91 
40 Shapiro M, Wilson RK, Casar G, Bloom K, Teague R. Work of breathing through different sized endotracheal tubes. Crit Care Med 1986;14:1028-31.

41 Fiastro JF, Habib MP, Quan SF. Pressure support compensation for inspiratory work due to endotracheal tubes and demand continuous positive airway pressure. Chest 1988;93:499-505.

42 Marini JJ, Capps JS, Culver BH. The inspiratory work of breathing during assisted mechanical ventilation. Chest 1985;87:612-8.

43 Kobylarz EJ, Daubenspeck JA. Immediate diaphragmatic electromyogram responses to imperceptible mechanical loads in conscious humans. F Appl Physiol 1992;73:248-59. 44 Wysocki M, Tric L, Wolff MA, Gertner J, Millet H, Herman with acute respiratory failure. Chest 1993;103:907-13. 